\begin{tabular}{llllllllllll} 
O P E R A T I O N S R E S E A R C H A N D D E C I S I O N S \\
\hline No. 1
\end{tabular}

DOI: $10.37190 /$ ord210101

\title{
INSPECTING DEBT SERVICING MECHANISM IN NIGERIA USING ARMAX MODEL OF THE KOYCK KIND
}

\author{
VIRTUE U. EKHOSUEHI ${ }^{1 *}$, DAVID E. OMOREGIE ${ }^{2}$ \\ ${ }^{1}$ Department of Statistics, University of Benin, P.M.B. 1154, Benin City, Nigeria \\ ${ }^{2}$ Monetary Policy Department, Central Bank of Nigeria, Abuja
}

The burden of external debt affects the wellbeing of an economy (or a country) by making the economy vulnerable to external shocks and crowding out investment. When dealing with debt management in indebted poor countries like Nigeria, the rational approach is to allocate a portion of export earnings for debt service payments. Along this line, there is a need to identify the link between debt servicing and export earnings. Hence, the current and long-run effects of export earnings on debt service payments are modelled as a single-input-single-output discrete-time dynamical system within the framework of the Autoregressive moving average explanatory input model of the Koyck kind (KARMAX). The KARMAX model is identified for Nigeria using data from the World Bank database from 1970 to 2018 based on the maximum likelihood (ML) method, and the obtained results are compared to the prediction error and the instrumental variable methods. From a theoretical perspective, the KARMAX specification identified by the ML method is more ideal and inspiring. By doing so, this article contributes to the literature on the econometrics of public debt management.

Keywords: ARMAX model, debt management, debt servicing, distributed-lag model, export earnings, Koyck model

\section{Introduction}

This paper aims to examine the debt servicing mechanism in Nigeria, using the ARMA model augmented by one explanatory variable (export earnings) and with geometric decay for lags distribution. The paper employs the maximum likelihood (ML) method to investigate this subject and compares the results with two other methods of the MATLAB software.

*Corresponding author, email address: virtue.ekhosuehi@uniben.edu Received 5 July 2020, accepted 28 January 2021 
The subject of external debt has received considerable attention in the literature (e.g., $[2,20,21,25,27])$. Many researchers provide advice on the sustainability of external debt stock $[20,23]$. There is a body of research on the use of indicators for external debt vulnerability and the economic well-being of a country based on the debt stock [1]. While respecting the debt indicators, the idea of entropy is introduced [24] as well as the optimal control of external debt dynamics [10]. Some useful results pointing to the need for debt forgiveness are obtained. Of specific importance is the external debt crisis in sub-Saharan Africa [9, 26].

Rising external debt stock in highly indebted poor countries (HIPCs) including Nigeria invigorates a perturbing issue on the burden of debt service payments. It is important when servicing external debt from export earnings to be able to determine the current and long-run effects of export earnings on debt service payments and thus evade possible trauma on its sustainability. This paper is a research study expounded in this direction. It considers a distributed lag methodology to examine the relationship between external debt service payments and export earnings, using data from the World Bank database for Nigeria from 1970 to 2018. The central focus is to describe the debt servicing-export earnings nexus by the autoregressive moving average explanatory input model of the Koyck kind (KARMAX). Despite the copiousness of the applicability of Autoregressive Moving Average Explanatory Input (ARMAX) models to single-input-single-output discrete-time dynamical systems [7, 19], researchers have not given any thought to the possibility of using such models to examine debt management systems. This creates a gap that this study intends to fill. The KARMAX specification for debt servicing is very inspiring because of its ability to conveniently express export earnings in terms of its current and long-run effects on external debt service payments.

A general single-input-single-output discrete-time dynamical system can be described by an ARMAX model defined by the linear stochastic difference equation of the form [30]:

$$
A\left(q^{-1}\right) y(t)=B\left(q^{-1}\right) u(t)+C\left(q^{-1}\right) w(t)
$$

where $y(t)$ is the output of the linear system, $u(t)$ is the input, $w(t)$ stands for the source of the disturbance and $q^{-1}$ is the unit backward shift operator, which delineates the following polynomials

$$
\begin{gathered}
A\left(q^{-1}\right)=1-a_{1} q^{-1}-\cdots-a_{n} q^{-n} \\
B\left(q^{-1}\right)=b_{1} q^{-1}+\cdots+b_{m} q^{-m} \\
C\left(q^{-1}\right)=c_{0}+c_{1} q^{-1}+\cdots+c_{n} q^{-n}, \quad c_{0}=1
\end{gathered}
$$


The polynomial $A\left(q^{-1}\right)$ is a Hurwitz polynomial that has all zeros strictly outside the unit disc. The input $u(t)$ is assumed to be stationary and the disturbance source $w(t)$ is assumed to be white noise and statistically uncorrelated with $u(t)$ for known values of $m, n$. When $m, n$ are specified to be $m=0$ and $n=1$, we have the ARMAX model of the Koyck kind, that is, KARMAX. The KARMAX model only supports time-domain data with single input without delay and single output at current value together with one-period lag. If $m=n=1$, we have the KARMAX model with delayed input.

The ARMAX model is preferred to other time-based domain models, as the autoregressive (AR) model and the autoregressive moving average (ARMA) model, because it is capable of integrating explanatory inputs in the dynamical system. In particular, the AR and the ARMA processes are suitable for modelling a dynamic system with no inputs.

There is extensive literature on the ARMAX models as a kind of dynamic models commonly used in the representation of stochastic linear systems found in practice [14, 19]. For example, the sales and advertising effects model [7], the ARMAX model with extra delayed output [30] and the damage identification model for civil engineering structures [19].

Regarding economic modelling of external debt stock in relevant macroeconomic variables, the autoregressive distributed lag (ARDL) model [2, 9, 27], regression analysis $[20,26]$, and vector autoregressive (VAR) model [11, 25], are widely used. To the best of our knowledge, there is little or no study on modelling the impact of export earnings on debt service payments with or without the use of ARMAX model. This study advances the application areas of the ARMAX model of the Koyck kind (KARMAX) to a debt-servicingexport-earnings mechanism. More specifically, debt service payments are represented as a stream of export earnings over time. This approach is particularly motivated by the aim to uncover the current and long-run effects of export earnings on debt servicing (in Nigeria) on the assumption that more recent export earnings have a greater influence on the debt service payments than the more remote ones. Since the Koyck geometric lag model allows for modelling the dynamics of debt service payments on this assumption, it is very useful for the present study. From the point of view of the infinite distributed lag methodology, the geometric lag model is transformed to the KARMAX model.

This study is also motivated by the need to aid policymakers with certain technical tools to have a more realistic debt servicing target, and this includes the building of technique-dependent tools for debt service payments projections. In part, there should be a guiding principle on the proportion of earnings that should be earmarked for debt servicing. Setting this proportion is nontrivial. When the proportion is too small, the country will not be able to keep up with its debt service obligations and will have to cope with the austere consequences of mounting debt arrears; when the proportion is too large, the investible funds that could have been spent on infrastructure and other productive ventures are depleted [4]. For this reason, there is a need for a technique- 
-dependent tool to assist policymakers in framing better policies on the capacity to repay loans beforehand. This study contributes to the debt management practice in Nigeria by attempting to quantify the current and the long-run effects of export earnings on debt service payments using relevant historical data compiled annually.

In the spirit of [12], the maximum likelihood (ML) method is a more appropriate tool to identify the KARMAX model. The method involves constructing the score vector and then setting it to zero and before solving for the parameters iteratively until the current solution is not significantly different from the past one. In order not to do away with other techniques in the literature for this same purpose [30], the prediction error (PE) method and the instrumental variable (IV) method, which are available in MATLAB, are considered. We compare the results of the methods using the Akaike information criterion (AIC) and the Bayesian information criterion (BIC).

\section{Related works}

The severity of Nigeria's external debt has been a subject of great concern as it has continued to hamper economic growth and worsened the balance of payments. Even after the debt cancellation granted to Nigeria in 2005, its external debt profile has grown quite rapidly over a relatively short period. Nigeria had the notoriety of being categorised as a heavily indebted poor country (HIPC). Most debtor countries, classified as HIPCs, started experiencing debt crisis and difficulty in debt service payments in 1980 [27]. The debt crisis is the direct cause of unsustainable external debt [20]. Debt servicing difficulties in Nigeria have heightened concern among researchers and policymakers as to whether the country can manage its burgeoning debt [26]. The International Monetary Fund (IMF) and World Bank have made substantial efforts to assist Nigeria and other HIPCs to ameliorate their debt-depressed situations by proposing strategies, such as the Baker Plan, the Market Menu, debt-equity swaps, and Brandy Plan, but all these efforts to stem the tides appear to be inconsequential $[20,26]$. Nigeria has made several efforts to deal with the notoriety of being regarded as HIPC, but there appears to be only minimal progress. The efforts include a projection of debt service payments, a compilation of relevant information and data on a regular and consistent basis, regulation and control of the level and composition of external indebtedness, and screening individual loans contracted by both the public and private sectors [26].

As a concerted effort to considerably improve debt-servicing capacity, most HIPCs allocate a part of their export earnings for debt service payments [26]. In Nigeria for instance, it can be said that the export earnings are a potential conduit for external debt servicing. Export earnings may motivate the willingness to service debt. One may think of its use for debt servicing as one that may have arisen from the failure to use external debt contracted in the past to develop income-generating and productive ventures within 
the debt-distressed country so that the only option available to the government to service the debt is a foreign exchange from export. This study pays close attention to external debt servicing based on export earnings in Nigeria.

To get some more depth useful to the present study, a snapshot of Nigeria's external debt is provided. In the early 1950 s, external loans were unnecessary for Nigeria because of the substantial export earnings, enhanced external reserves and grants from the United Kingdom. Obadan [22] traces the origin of external borrowing in Nigeria to 1958 when a loan of US\$28 million was contracted from the World Bank for railway construction. During the first two decades of Nigeria's political independence in 1960, external debt obligations did not present a serious issue. This was because the debt and debt service payments were small concerning export earnings. According to Sanusi [28], the problem of external debt in Nigeria became a subject of interest in the early 1980s. This was primarily due to the collapse of oil prices in the international market. The later years experienced an increase in the debt profile in leaps and bounds. The phenomenal increase in debt stock can be attributed to several reasons including new loans, the capitalisation of unpaid interest charges on rescheduled debt obligations ${ }^{1}$, exchange rate fluctuations, low saving propensity, poor external debt management policies, wasteful economic policies, financing of long term projects by short term debt, declining foreign exchange earnings and diversion of loans into other unproductive ventures $[5,28]$.

In 1992, a substantial portion of the debt amounting to the U.S. \$ 5799.2 million was cancelled [22]. This debt relief, which was granted by the London Club of private/commercial creditors, was due to a debt buy-back arrangement. Even so, the benefit from the London Club relief was short-lived as a result of interest in debt service arrears and depreciation of the U.S. dollar against other major currencies in which the external debt was dominated. In 1996, Nigeria recorded another significant reduction in external debt by effective implementation of certain debt management strategies, including debt conversion scheme like debt-equity swap. Before 2005, the debt owed to the Paris Club of official creditors was a major problem of Nigeria's debt management. Nonetheless, there was a respite in 2005 when Nigeria recorded a huge success from the Club via debt forgiveness. It is rather sad to note that even with this debt relief and other debt management strategies under various operating regulations; the external debt stock continues to grow unabated in such a fashion that it now poses a problem of sustainability [23].

Perhaps it is difficult to preclude the quest for external loans given the balance of payment problems, budget deficits, reduced export earnings and domestic savings gap. Even then, this should not be a reason for the indiscriminate and unabated accumulation of external debt as the debt service burden is deleterious to the economy. For example, the increase in government budget deficit, the reduction in investible funds, the debt overhang, and crowding-out effects all have negative effects on economic growth [3].

${ }^{1}$ There is no provision for interest cancellation in debt rescheduling. 
As reported by Obadan [22], the debt management measures adopted in Nigeria have not yielded satisfactory results: the embargo on new loans and the debt restructuring were only temporary, while the pursuit for external loans remains persistent.

There is a plethora of research on external debt and debt management policy, as well as an extended discussion on related materials on Nigeria's external debt structure $[22,26]$. While some authors focus on the debt problem, others investigate the economic implications of the debt management measures [3, 5, 6, 28]. This study takes a new look at the debt problem by considering the debt serving mechanism from export earnings, using a different approach in the literature that is based on the ARMAX model framework.

\section{Data and methodology}

\subsection{Description of data}

Throughout this study, the focus remains on the possibility of using export earnings for debt service payments in Nigeria, so data on other external debt indicators and other countries are not considered. The primary data sources for this study are obtained from the World Bank database from 1970 to 2018 as listed below.

1. Export earnings. These include the value in U.S. dollars of merchandise, freight, insurance, transport, travel, royalties, license fees, and other services, such as communication, construction, financial, information, business, personal, and government services, but exclude compensation of employees and investment income (formerly called factor services) and transfer payments ${ }^{2}$.

2. Debt service payments cover debt servicing on external debt, public and publicly guaranteed in U.S. dollars ${ }^{3}$.

\subsection{The design}

The nexus between export earnings and debt service payments is described by the ARMAX model arising from a distributed lag specification. Lags occur because it takes time for debt managers to scrutinise export earnings over time before concluding what the debt service payments should be. Distributed lag models are perhaps the most popular approach to model a dynamic system in economics $[8,17]$.

We assume that debt service payments are made based on the current and past export earnings. It is important to look at the past as well as at current export earnings to

${ }^{2}$ https://data.worldbank.org/indicator/NE.EXP.GNFS.CD?locations=NG

${ }^{3} \mathrm{https}$ ://data.worldbank.org/indicator/DT.TDS.DPPG.CD?locations=NG 
account for the contribution of past export earnings on the allocation of funds for debt service obligations in the current period. Thus, the effect of export earnings on debt service payments is not just instantaneous but distributed over time.

We believe that the debt managers are concerned with actual export earnings when allocating funds for debt service payments. Since many HIPCs devote a substantial portion of their export earnings on debt servicing [26], we concentrate on the impact of export earnings on debt service payments rather than exploring further other factors that may influence the magnitude of debt servicing.

Let $D=\left\{\left(d_{t}, X_{t}\right): t=1,2, \ldots, T\right\}$ be a data set on debt service payments $d_{t}$ and export earnings $X_{t}$ at each period $t$, where $T$ is the length of the observation sequence. It is desirable to have data on $d_{t}$ and $X_{t}$ as large as possible. Assume that the link between debt service payments $d_{t}$ and export earnings $X_{t}$ is given by the geometric lag model

$$
d_{t}=\beta \sum_{i=0}^{\infty} \lambda^{i} X_{t-i}+\varepsilon_{t}, \quad \beta>0, \quad 0<\lambda<1
$$

where $\varepsilon_{t}$ is uncorrelated with zero mean and constant variance. Interest is focussed on the geometric declining lag pattern. The geometric lag model is realistic from the point of view of the debt management practice in Nigeria [22]. Although the lagging of export earnings series does not obviate the fact that the number of observations decreases and the number of parameters to be estimated increases with the lagging variable, yet the infinite distributed lag specification is more convenient as we do not have to deal with the problem of what the lag length should be. The issue of the endless number of parameters and the reduction in the number of observations are easily manoeuvred using the Koyck transformation.

The main study parameters in this paper are $\lambda$ and $\beta$. The parameter $\lambda$ is the retention rate. If $\lambda \rightarrow 1$, then we can infer that the remote export earnings have a substantial impact on debt service payments. If $\lambda \rightarrow 0$, then it can be said that the past export earnings have negligible impacts on debt service payments. Thus, $\lambda$ is a measure of the degree to which past export earnings are reflected in the current level of debt service payments. The speed of adjustment, that is, the extent current export earnings performance gets translated in the present decision to service debt is $1-\lambda$. The estimated value $\lambda$ has much to do with the remote values of export earnings that are important. As a result, there is no need to argue on the right length of lags.

The parameter $\beta$ supplies information on the current effect of export earnings on debt servicing. The long-run effect is given by

$$
\beta \sum_{i=0}^{\infty} \lambda^{i}=\frac{\beta}{1-\lambda}
$$


The value of $\beta /(1-\lambda)$ has a far-reaching implication as it is used to assess the stability of the system. When $\beta /(1-\lambda)>1$, then debt servicing from export earnings would be dynamically unstable in the long run.

This study assumes prior information about the behaviour of $\beta$ that it follows the Koyck model of the geometric decaying lag pattern. This assumption is well known in the literature $[12,16]$. Theil and Fiebig [29] earlier justified the Koyck specification of distributed lags based on prior information/assumption using the maximum entropy approach. This is the motive for our assumption on the behaviour of $\beta$. The decaying geometric lag pattern is reasonable in the sense that the trend in Nigeria's external debt started from a virtually non-existent debt situation before 1978 [26] and so the portion of export earnings used for debt service payments was negligible.

Introducing the unit backward shift operator $q^{-1}$, equation (2) can be expressed as

$$
d_{t}=\beta\left(1-\lambda q^{-1}\right)^{-1} X_{t}+\varepsilon_{t}
$$

Without any ado, this leads to

$$
d_{t}=\beta X_{t}+\lambda\left(d_{t-1}-\varepsilon_{t-1}\right)+\varepsilon_{t}
$$

Equation (5) is the ARMAX model of the Koyck kind (KARMAX). This model saves the endless number of calculations and eliminates the multicollinearity problem in the distributed lag specification. From the debt management perspective, the second term is the part of debt service payments that falls due in the preceding period.

\subsection{Parameter estimation}

It does appear that the estimation of parameters in equation (5) is nontrivial as the equation contains three explanatory variables $\left(X_{t}, d_{t-1}, \varepsilon_{t-1}\right)$ with two parameters $(\beta, \lambda)$. If the problem were a zero-period lag model (that is $\lambda=0$ ), then there is nothing to worry about as the parameter estimation is straightforward. Such a problem is that of a static model in which debt service payments respond instantaneously to changes in export earnings. The effect can be estimated by the ordinary least squares (OLS) method as

$$
\hat{\beta}_{0}=\frac{\sum_{t=1}^{T} X_{t} d_{t}}{\sum_{t=1}^{T} X_{t}^{2}}
$$


Parameter estimation via the least-squares criterion is perhaps the most studied and implemented scheme of model identification. However, for the problem at hand, the OLS method is not a suitable approach as many of the assumptions are violated. For instance, the OLS estimates are bias in small samples, inconsistent, asymptotically biased and the error component is autocorrelated [16]. Even for a finite distributed lag model with a known length of lag, the OLS is not appropriate and this is largely due to the multicollinearity problem among the explanatory variables, which are lagged observations for the same variable [13]. Lund and Miner [18] examine the sources of error (e.g., randomness, exclusion of relevant variables and errors of measurement) in distributed lag models and their consequences for the OLS estimation, viz. inconsistent and inefficient estimates. Thus, the least squares method is not a sound approach for identifying KARMAX $[12,15]$.

There are other variants of the standard least-squares method for identifying the ARMAX models frequently encountered in real-world applications (for instance, the ARMAX and the IV4 codes in MATLAB for the prediction error (PE) method and the instrumental variable (IV) method, respectively). Following an extant theoretical guide [12], this study identifies KARMAX using the maximum likelihood (ML) method.

The ML estimates can be obtained from the relevant historical data on the macroeconomic variables, $D=\left\{\left(d_{t}, X_{t}\right): t=1,2, \ldots, T\right\}$, by optimising the log-likelihood function, which is given by

$$
\ln L(\beta, \lambda)=-\left(\frac{T-1}{2}\right) \ln 2 \pi \sigma^{2}-\sum_{i=2}^{T} \frac{\varepsilon_{t}^{2}}{2 \sigma^{2}}
$$

where $\left\{\varepsilon_{t}\right\}$ are recursively defined as

$$
\varepsilon_{1}=0, \varepsilon_{t}=d_{t}-\beta X_{t}-\lambda\left(d_{t-1}-\varepsilon_{t-1}\right), t=2,3, \ldots, T
$$

To accelerate computational time, the second term in equation (6) is minimised, since the first term is not affected by the data set. Let $S=-\sum_{i=2}^{T} \frac{\varepsilon_{t}^{2}}{2 \sigma^{2}}$, so that the deviance for the distribution is $-2 S$. That is, $S$ is defined to be

$$
S=-\frac{1}{2 \sigma^{2}} \sum_{i=2}^{T}\left(d_{t}-\beta X_{t}-\lambda\left(d_{t-1}-\varepsilon_{t-1}\right)\right)^{2}
$$

Then the score vector of $\beta, \lambda$ is given by 


$$
\mathbf{U}(\beta, \lambda)=\left[\begin{array}{l}
u_{1} \\
u_{2}
\end{array}\right]
$$

where $u_{1}, u_{2}$ are the partial derivatives of $S$ concerning $\beta, \lambda$, respectively. Thus,

$$
u_{1}=\sum_{i=2}^{T} X_{t} \varepsilon_{t}
$$

and

$$
u_{2}=\sum_{i=2}^{T}\left(d_{t-1}-\varepsilon_{t-1}\right) \varepsilon_{t}
$$

The problem snowballs into solving, $\mathbf{U}(\beta, \lambda)=\left[\begin{array}{l}0 \\ 0\end{array}\right]$ for $\beta$ and $\lambda$. This problem can be resolved by applying the Newton-Raphson method, which involves solving the iterative equation

$$
\boldsymbol{\Phi}^{(k+1)}=\boldsymbol{\Phi}^{(k)}-\left[\mathbf{H}\left(\boldsymbol{\Phi}^{(k)}\right)\right]^{-1} \mathbf{U}\left(\boldsymbol{\Phi}^{(k)}\right), \quad k=0,1,2, \ldots
$$

provided that $\operatorname{det}\left(\mathbf{H}\left(\boldsymbol{\Phi}^{(k)}\right)\right) \neq 0$, where $\boldsymbol{\Phi}^{(k)}=\left[\begin{array}{l}\beta^{(k)} \\ \lambda^{(k)}\end{array}\right], \mathbf{H}\left(\boldsymbol{\Phi}^{(k)}\right)$ is the Hessian matrix of the log-likelihood function evaluated at $\boldsymbol{\Phi}^{(k)}$ and $-\left[\mathbf{H}\left(\boldsymbol{\Phi}^{(k)}\right)\right]^{-1}$ is the dispersion matrix at the $k$ th number of iteration. Starting with an initial guess $\beta^{(0)}=\lambda^{(0)}=0$, successive approximations are obtained using equation (11) and it stops when the parameters $\beta^{(k+1)}$ and $\lambda^{(k+1)}$ do not significantly differ from $\beta^{(k)}, \lambda^{(k)}$ any more.

\section{Empirical results}

Looking at the dynamics of debt service payments and export earnings by their levels (Figs. 1a, 1b), one could say that the two variables do not follow the same trajectory. Preliminary investigation using Pearson's correlation coefficient indicates that there is no significant relationship between the two variables. Hence, there is a strong likelihood that multicollinearity will not be present when the variables are used as explanatory variables in the KARMAX model. As apparent from the data (Fig. 2) and judging by 
the $30 \%$ threshold [5], the debt service payments to export ratio exceeded this threshold between 1983 and 1986, and in 1988 and 1994. These years indicate periods of undue burden on export earnings.
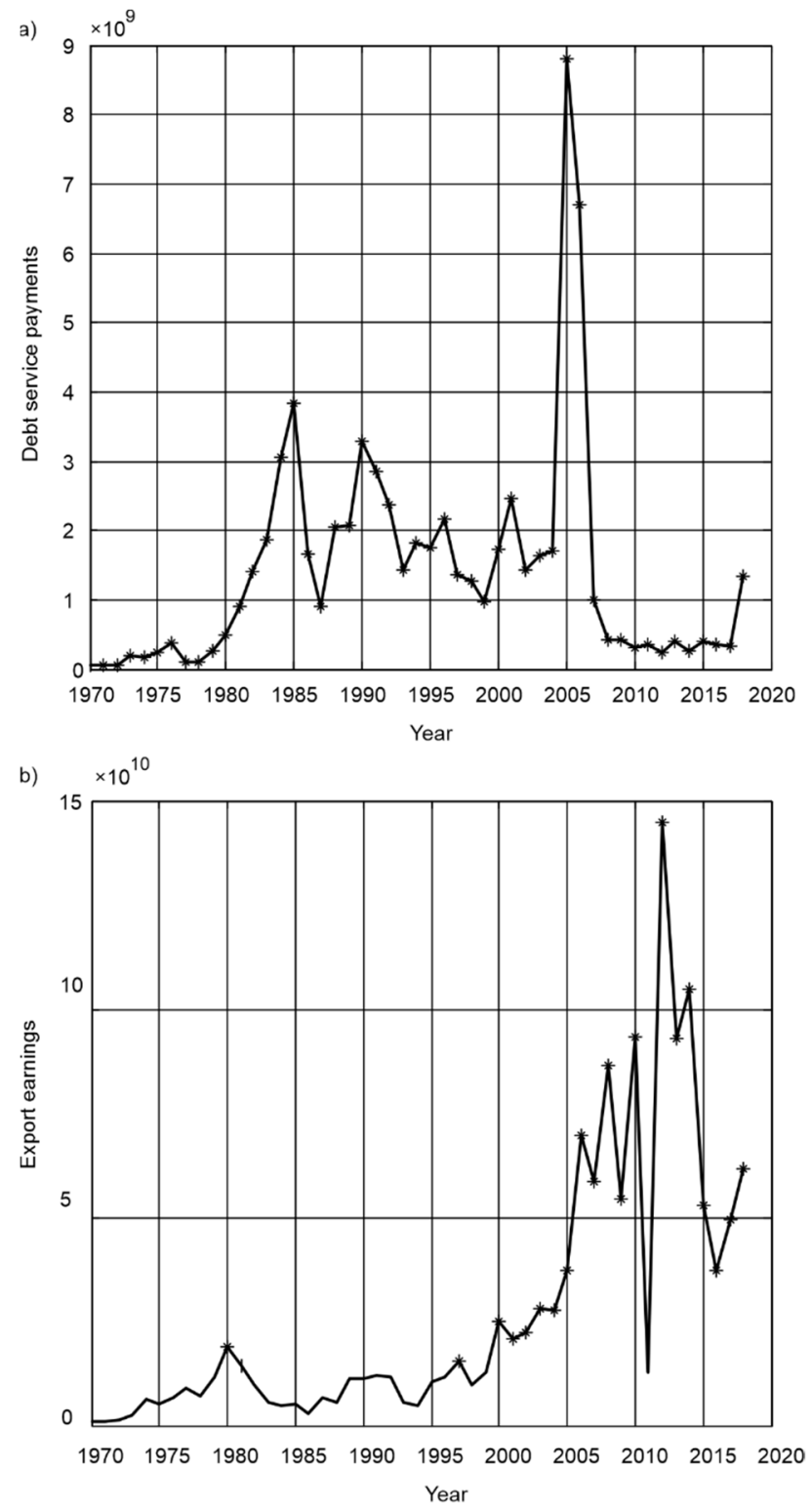

Fig. 1. Dynamics of debt service payments (a) and export earnings (b) from 1970 to 2018 


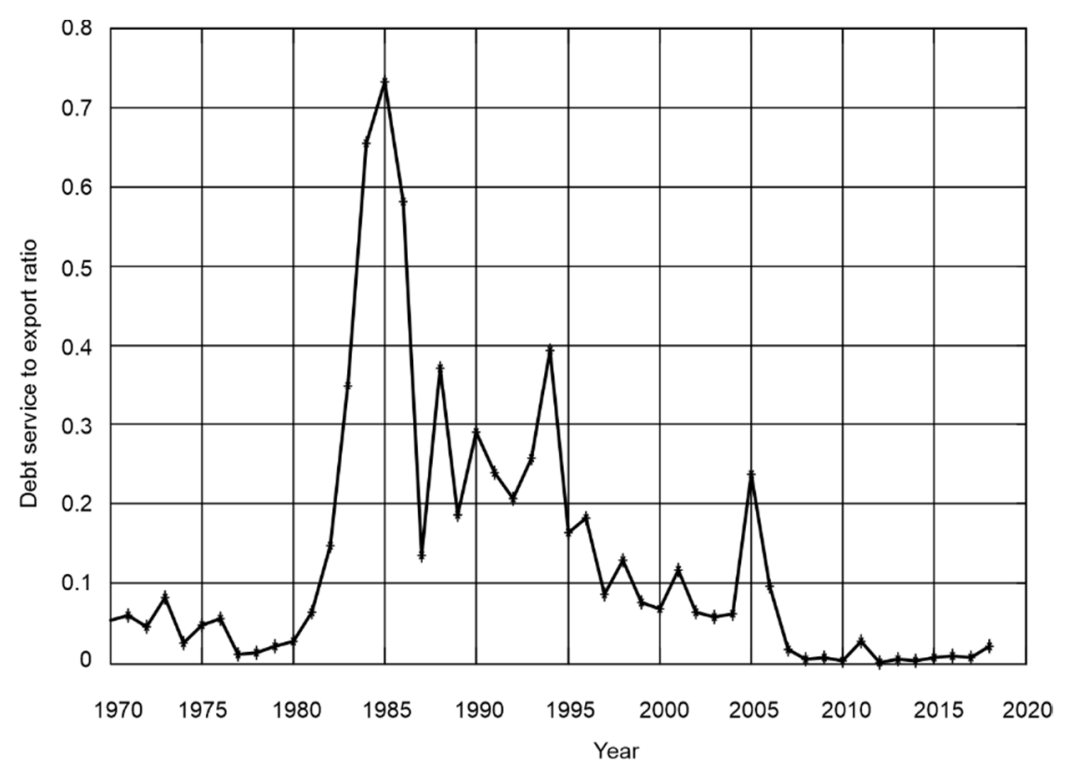

Fig. 2. Debt service payments to export ratio from 1970 to 2018

Since the levels of debt service payments and export earnings are under study, the stationarity of processes generating the data should be cautiously verified. To achieve this, we employ the augmented Dickey-Fuller (ADF) test, which examines the null hypothesis that a unit root is present in a time series sample. We implement the ADF testing procedure using the dfARTest function in the MATLAB statistics toolbox. The test reveals that the null hypothesis is rejected for both time series data (on debt service payments and export earnings). Thus, we conclude that the series are stationary and that the lagged level is relevant.

Consistent with recent literature [12], the KARMAX model is identified using the ML method. For the final approximation, the dispersion matrix is

$$
-\left[\mathbf{H}\left(\left[\begin{array}{l}
0.0185 \\
0.1136
\end{array}\right]\right)\right]^{-1}=10^{19} \times\left[\begin{array}{cc}
0.0003 & -0.0142 \\
-0.0142 & 0.8728
\end{array}\right]
$$

and the deviance is

$$
D=\frac{1}{\hat{\sigma}^{2}} \sum_{t=2}^{T} \hat{\varepsilon}_{t}^{2}=59.0767
$$

The deviance does not exceed the upper $5 \%$ point of the $\chi^{2}(46)=62.8296$. The estimated parameters, $\hat{\beta}=0.0185$ and $\hat{\lambda}=0.1136$, are significant at the $1 \%$ level. The 
value $\hat{\lambda}=0.1136$ indicates that past export earnings do not have a strong impact on current debt service payments. Against our expectation, the existence of substantial lags of export earnings on debt service payments is not corroborated. When we employ the equilibrium solution, the long-run effect is $\hat{\beta} /(1-\hat{\lambda})=0.02$. This implies that the system is dynamically stable.

We find whether the debt service payments are arbitrary or based on export earnings. Under the null hypothesis that the external debts are arbitrarily serviced, $\beta=0$, the deviance $D_{0}$ with $T-1$ degrees of freedom is $2.2808 \times 10^{20} / \sigma^{2}$. With the alternative hypothesis that external debt service payments are linked to export earnings via the KARMAX specification, the deviance $D_{1}$ with $T-3$ degrees of freedom is computed to be $1.9261 \times 10^{20} / \sigma^{2}$. The $F$ ratio is calculated as 4.2348 . This is an indication that the null hypothesis is not significant compared to $F(1,46)=4.0517$ at the $5 \%$ level of significance. Thus, we conclude that the debt service payments could not have been made arbitrarily.

We verify whether the residuals satisfy the default null hypothesis that the errors come from a distribution in the normal family, against the alternative that it does not come from a normal distribution using two normality test statistics: the Kolmogorov -Smirnov test and the Lilliefors test. The Kolmogorov-Smirnov test requires that the cumulative distribution function (CDF) be predetermined. That is, the null distribution should be completely specified. The test returns a $p$-value of $5.7535 \times 10^{-23}$ and a Kolmogorov-Smirnov value of 0.7143 with a critical value of 0.1903 . From the results, we cannot entirely conclude that the residuals come from a normal distribution. Since the CDF is estimated from the data, this test may not be accurate. For this reason, we think that the Lilliefors test should be more appropriate as the Lilliefors test is suitable when a fully specified null distribution is unknown. We implement the Lilliefors test in the MATLAB environment using the "lillietest" function. The results when the Lilliefors test is applied indicate that the residuals are normally distributed. This inference from the Lilliefors test provides a justification for the distributional assumption of the error term in the use of the ML method to identify the KARMAX model.

Digging deep into the problem at hand, the identified KARMAX model is compared to the PE and IV methods, which are accessed from the System Identification Toolbox in MATLAB. We compute the Akaike information criterion (AIC) and Bayesian information criterion (BIC) for each of the fitted models. A summary of the results is presented in Table 1. Table 1 contains the identification of the KARMAX model for debt service payments augmented by export earnings. From the obtained results, the retention parameter $\lambda$ can be determined as follows: $\lambda=0.1136$ for $\mathrm{ML}, \lambda=0.3861,0.5395$ for PE and $\lambda=0.5766$ for IV. These results for $\lambda$ lie within a sensible range $[0,1)$. For the PE method, the values of $\lambda$ are not approximately equal. 
Table 1. Performance of the ML method for KARMAX, the PE method and IV method

\begin{tabular}{|c|c|c|c|}
\hline Method & Model & AIC & BIC \\
\hline ML & $d_{t}=0.0185 X_{t}+0.1136\left(d_{t-1}-\varepsilon_{t-1}\right)$ & $2.1975 \times 10^{3}$ & $2.2012 \times 10^{3}$ \\
\hline PE & $A\left(q^{-1}\right) d_{t}=0.002569 X_{t}+C\left(q^{-1}\right) \varepsilon_{t}$ & $2.2769 \times 10^{3}$ & $2.2826 \times 10^{3}$ \\
\hline IV & $F\left(q^{-1}\right) d_{t}=0.001187 X_{t}+\varepsilon_{t}$ & $2.1649 \times 10^{3}$ & $2.1686 \times 10^{3}$ \\
\hline
\end{tabular}

$A\left(q^{-1}\right)=1-0.3861 q^{-1}, C\left(q^{-1}\right)=1+0.5395 q^{-1}$, and $F\left(q^{-1}\right)=1-0.5766 q^{-1}$.

The question that arises is which one of the values should be used as there is no objective means to decide on the estimate of $\lambda$ that is more appropriate. This creates another problem of identification. The PE method also produces the largest AIC and BIC values. As compared to the IV method, the IV is preferred, according to the AIC and BIC, as it has the smallest AIC and BIC values. In spite of this favourable estimation performance, the IV identification of the model is less interesting as the moving average part of the process is ignored. So the IV method of fitting the model produced a model that cannot be transformed back to the model specification in equation (5). From a theoretical perspective, the KARMAX specification identified by the ML method is more ideal and inspiring. Moving forward, we rely on the results from the ML method. Since $\lambda$ is a measure of how quickly past export earnings are reflected in the current repayment of loans, the value, $\lambda=0.1136$ indicates that the rate of decline of the impact of export earnings on debt service payments is $11.36 \%$. This implies that the impact of export earnings on debt service payments decline rapidly. Thus, the more remote export earnings have negligible impact on current debt service payments. It follows that each of the $i$-lagged values $X_{t-i}$ has a progressively smaller impact of magnitude $\hat{\beta} \hat{\lambda}^{i}=(0.0185)(0.1136)^{i}$ on debt service payments. From the ML identification of the KARMAX model, we are able to conclude that the debt service payments from export earnings is dynamically stable for Nigeria in the long-run as $\hat{\beta} /(1-\hat{\lambda})=0.02<1$. This is a contribution to a case in debt management practice. The mean lag of the process is $\hat{\lambda} /(1-\hat{\lambda})=0.1282$ years. This value implies that $11.36 \%$ of the impact of an increase in export earnings will be felt within one month and two weeks. This length is short for the process, which is assumed to evolve annually. Thus, the capacity for Nigeria to repay loans (interest and amortisation) may be as well based on the current export earnings.

\section{Conclusion}

This study has contributed to the literature on debt analysis by framing the ARMA model augmented by one explanatory variable (export earnings) and with geometric decay for lags distribution. Rather than relying on intuition to make specific decisions 
on debt service payments, this study proposes the ARMAX model of the Koyck kind (KARMAX) for this same purpose. Our choice of KARMAX was influenced by prior knowledge on the debt management practice in HIPCs, according to the relevant literature [26]. Our approach addresses instances that may arise when the current and longrun effects of an explanatory input on debt servicing are required. In this case, the KARMAX model is the primary option. This study considers export earnings as such an explanatory input. The study does not consider efficiency in the use of external debt. Thus, it does not delve into whether loans are contracted for political expediency or for economic viability of projects with a view of paying back the debt. To a certain extent, the obtained results show that the KARMAX approach is appropriate as a handy tool in the quest for a debt-servicing-export-earnings mechanism in Nigeria. There may be a need to include other macroeconomic variables (for example, GDP, external reserve, and national fiscal revenue) in relation to the debt servicing obligations. This opens a new window of motivation for a multiple-input-single-output ARMAX model or other analytical framework to be identified for the debt servicing mechanism. This would lead to the analysis of a multivariate data set with the relevant macroeconomic variables selected using feature selection techniques. To alleviate the possible bottleneck associated with the data requirements, there should be a comprehensive and up-to-date statistical reporting on various macroeconomic variables associated with debt management. This is because such information is crucial for a proper analysis of debt service payments. The Central Bank of Nigeria has started such documentation, but there is a strong need to do more by providing information on the relevant variables for the previous years.

\section{Acknowledgement}

The authors are grateful to the anonymous referees for their valuable comments and suggestions the incorporation of which has enhanced the presentation and ideas of the present paper.

\section{References}

[1] AbDullah F.A., Development of an advance warning indicator of external debt servicing vulnerability, J. Int. Bus. Stud., 1985, 16 (3), 135-141.

[2] Abdullahi M.M., Abu BaKar Bt. N.A., Hassan S.B., Determining the macroeconomic factors of external debt accumulation in Nigeria. An ARDL bound test approach, Proc. Soc. Beh. Sci., 2015, 211, 745-752.

[3] AJAYI S.I., Macroeconomic approach to external debt. The case of Nigeria, AERC Research Paper 8, Initiatives Publishers, Nairobi 1991.

[4] AKPOKODJE G., The effect of export earnings fluctuations on capital formation in Nigeria, AERC Research Paper 103, Nairobi 2000.

[5] Anyanwu J.C., Nigerian Public Finance, Joanes Educational Publishers, Ltd., Onitsha 1997.

[6] ARSLAnalP S., HenRy P.B., Is debt relief efficient?, J. Fin., 2005, 60 (2), 1017-1051.

[7] Bass F.M., Clarke D.G., Testing distributed lag models of advertising effect, J. Market. Res., 1972, 9 (3), 298-308. 
[8] Benjamin J.D., Jud G.D., OKoruwa A.A., Forecasting the stock of retail space using the Koyck distributed lag model, J. Prop. Res., 1993, 10 (3), 185-192, DOI: 10.1080/09599919308724092.

[9] Edo S., OsAdolor N.E., DAdiNG I.F., Growing external debt and declining export: The concurrent impediments in economic growth of sub-Saharan African countries, Int. Econ., 2019, DOI: 10.1016 /j.inteco.2019.11.013

[10] Ekhosuehi V.U., Osagiede A.A., A debt model for LDCs and HIPCs, ABACUS: J. Math. Assoc. Nigeria, 2007, 34 (2B), 447-451.

[11] Essien S.N., Agboegbulem N.T.I., Mba M.K., Onumonu O.G., An empirical analysis of the macroeconomic impact of public debt in Nigeria, CBN J. Appl. Stat., 2016, 7 (1), 125-145.

[12] Franses P.H., VAN OeSt R., On the econometrics of the geometric lag model, Econ. Lett., 2007, 95, 291-296, DOI:10.1016/j.econlet.2006.10.023.

[13] GÜler H., GÜltay B., KaÇIRANLAR S., Comparisons of the alternative biased estimators for the distributed lag models, Comm. Stat. Sim. Comp., 2015, DOI:10.1080/03610918.2015.1053919.

[14] Hannan E.J., DunSMUIR W.T.M., Deistler M., Estimation of vector ARMAX models, J. Multiv. Anal., 1980, 10, 275-295.

[15] Jia L.-J., KANAE S., YANG Z.-J., WADA K., On parameter estimation of ARMAX model via BCLS method, IFAC Syst. Ident., Rotterdam 2003, 1113-1118.

[16] Koutsoyiannis A., Theory of Econometrics, 2nd Ed., Pakgrave, New York 1977.

[17] LAGARIAS J.C., Effects of misspecification of lag structure in certain two-variable distributed lag models, Computers Math. Appl., 1991, 22 (10), 3-23.

[18] Lund P.J., Miner D.A., The nature of the error term in distributed lag models, Appl. Econ., 1975, 7 (3), 185-194, DOI: 10.1080/00036847500000020.

[19] Mei L., Li H., Zhou Y., Wang W., Xing F., Substructural damage detection in shear structures via ARMAX model and optimal subpattern assignment distance, Eng. Struct., 2019, 191, 625-639, https://doi.org/10.1016/j.engstruct.2019.04.084

[20] Muhanji S., OJAH K., Management and sustainability of external debt: A focus on the emerging economies of Africa, Rev. Dev. Fin., 2011, 1, 184-206.

[21] MuHANJ S., OJAH K., External shocks and persistence of external debt in open vulnerable economies: The case of Africa, Econ. Model., 2011, 28, 1615-1628.

[22] Obadan M.I., External debt and management policy, [In:] M.A. Iyoha, C.O. Itsede (Eds.), Nigerian Economy: Structure, Growth and Development, Mindex Publishing, Benin City 2002, 327-350.

[23] Омотоsнo B.S., Bawa S., Doguwa S.I., Determining the optimal public debt threshold for Nigeria, CBN J. Appl. Stat., 2016, 7 (2), 1-25.

[24] Osagiede A.A., Ekhosuehi V.U., Extending entropy stability measure to external debt structure, J. Sci. Technol., 2007, 27 (3), 156-162.

[25] QURESHI I., LIAQAT Z., The long-term consequences of external debt: Revisiting the evidence and inspecting the mechanism using panel VARs, J. Macroecon., 2020, 63, 103-184, https://doi.org/10.1016 /j.jmacro.2019.103184

[26] RAHEEM M.I., Assessing and managing external debt problems in Nigeria, World Dev., 1994, 22 (8), $1223-1242$.

[27] Siddique A., Selvanathan E.A., Selvanathan S., The impact of external debt on growth. Evidence from Highly Indebted Poor Countries, J. Pol. Model., 2016, http://dx.doi.org/10.1016/j.jpolmod.2016.03.011

[28] SanUSI G.P., The impact of oil export earnings on Nigeria's external debt, Working Paper, International Association for Energy Economics, USA, 2010.

[29] TheIL H., FiEBIG D., A maximum entropy approach to the specification of distributed lags, Econ. Lett., 1981, 7, 339-342.

[30] ZHENG W.X., On least-squares identification of ARMAX models, 15th Triennial World Congress, Barcelona, Spain, 2002, 391-396. 